\title{
Morphometrics of the Late Devonian conodont genus Palmatolepis: phylogenetic, geographical and ecological contributions of a generic approach
}

\author{
CATHERINE GIRARD ${ }^{1}$, SABRINA RENAUD $^{1} \&$ RAIMUND FEIST $^{2}$ \\ ${ }^{1}$ Université Lyon 1; CNRS, UMR5125 PEPS, Campus de la Doua, Batiment Géode, 2 rue Raphäl Dubois, 69622 Villeurbanne Cedex, France \\ (e-mail: catherine.girard@univ-lyon1.fr) \\ ${ }^{2}$ UMR 5554 'Institut des Sciences de l'Evolution', Université Montpellier II, Place Eugène Bataillon, C.C. 62, 34095 Montpellier Cedex 5,
} France

\begin{abstract}
Studying the palaeobiology of extinct organisms relies on assessing the relevant scale of morphometric differentiation corresponding to the evolutionary units in the group. On the time-slice of the latest Frasnian, sampled in nine outcrops from three distant palaeogeographical domains (Laurussia, northwest and northeast Gondwana), the morphological pattern of differentiation of the conodont genus of Palmatolepis was analysed based on the outline of its platform elements. A generic approach was used that challenged the concept of species in this genus but supported the distinction between two subgenera. In the samples considered here, Palmatolepis Palmatolepis includes the single species linguiformis, and Palmatolepis Manticolepis appears as a homogeneous group composed of a single species or a complex of closely related species. The former displays mostly an isometric growth whereas the allometric growth of the latter means that the difference between the two subgenera increases with the size of the elements. Shape difference of an element belonging to the feeding apparatus may be related to differences in ecology. Hence, the differences in size and shape between the two subgenera may be interpreted as related to differences in their ecological preferences and life history traits. J. Micropalaeontol. 26(1): 61-72, April 2007.
\end{abstract}

KEYWORDS: Palmatolepis, latest Frasnian, palaeoecology, Fourier analysis, ontogeny

\section{INTRODUCTION}

The concept of species in palaeontology always raises numerous problems. The application of the biological concept of species (Mayr, 1957) - reproductively isolated populations - cannot be applied to fossil organisms for obvious reasons. Except for recently extinct taxa in which ancient DNA can yield biologically relevant information on the degree of isolation of extinct populations (Cooper, 2005), this approach will not be applicable to more ancient fossils due to degradation of the DNA over time (Willerslev \& Cooper, 2005). Fossil species thus have to be defined by external morphological criteria, the only data that commonly persist in the long-term fossil record. However, genetic analyses of modern marine populations have recently cast some doubt on the biological relevance of such an approach. A growing body of evidence shows that a strong genetic structure is the rule rather than the exception within morphologically based species of planktic marine organisms, supposedly the most prone to mixing over a large geographical scale (de Vargas et al., 1999; Darling et al., 2000; Kucera \& Darling, 2002). However, fine-scale morphological variation seems to be associated often with genetic differentiation (de Vargas et al., $1999,2001)$. Such differentiation is also frequently related to environmental preferences that can thus be tracked back into the fossil record (Renaud \& Schmidt, 2003). This suggests that the use of morphometric methods may be a relevant approach to unravel palaeobiological characteristics of long-extinct animals.

The need to rely on morphological criteria is typically the case for conodonts, which became extinct at the end of the Triassic, $200 \mathrm{Ma}$ ago. Based on various analyses of the few complete fossils including soft parts, the animal is nowadays interpreted as a member of the Chordata and an early vertebrate more derived than either hagfish or lampreys (Donoghue et al., 2000).
The conodont animal displayed a complex feeding apparatus whose dissociated skeletal parts are found abundantly in fossil deposits. Reconstruction of the multi-element apparatus is a first step in the investigation of palaeobiological characteristics of these animals (Klapper \& Philip, 1971; Donoghue, 2001), but this limits considerably the number of specimens to be considered because of the rarity of complete apparatuses. Another approach is to focus on a single element of the complex apparatus, which displays numerous typical characters and evolves quickly through time. Such an approach is used for instance in mammalian studies where many interpretations can be based on the most characteristic tooth of a group (Misonne, 1969; Michaux, 1971). In this case, as in conodonts, the element is expected to have evolved with phylogeny and ecology, especially diet, as a part of a feeding apparatus, composed of different element types named $\mathrm{M}, \mathrm{S}$ (ramiforms) and $\mathrm{Pa}$ and $\mathrm{Pb}$ (platforms). Conodont elements could further vary with the growth of the animal, since they are composed of lamellae that were deposited successively around an initial growth centre. As conodont elements are susceptible to fragmentation ( $\mathrm{M}$ or $\mathrm{S}$ elements), and other elements $(\mathrm{Pb})$ are often under represented, only the platform element $\mathrm{Pa}$ is used extensively for biostratigraphy. The Upper Devonian genus Palmatolepis is characterized by such a rapidly evolving and highly characteristic Pa element within the apparatus, which has been used for most of the taxonomy of the group (Müller, 1956; Ziegler \& Sandberg, 1990; Klapper \& Foster, 1993; Schülke, 1995).

This paper aims to investigate the relevance of a morphometric approach to address palaeobiological questions regarding Palmatolepis. Platform elements of this genus were studied using a morphometric analysis of their platform outline. The study is focused on the latest Frasnian and includes samples from 


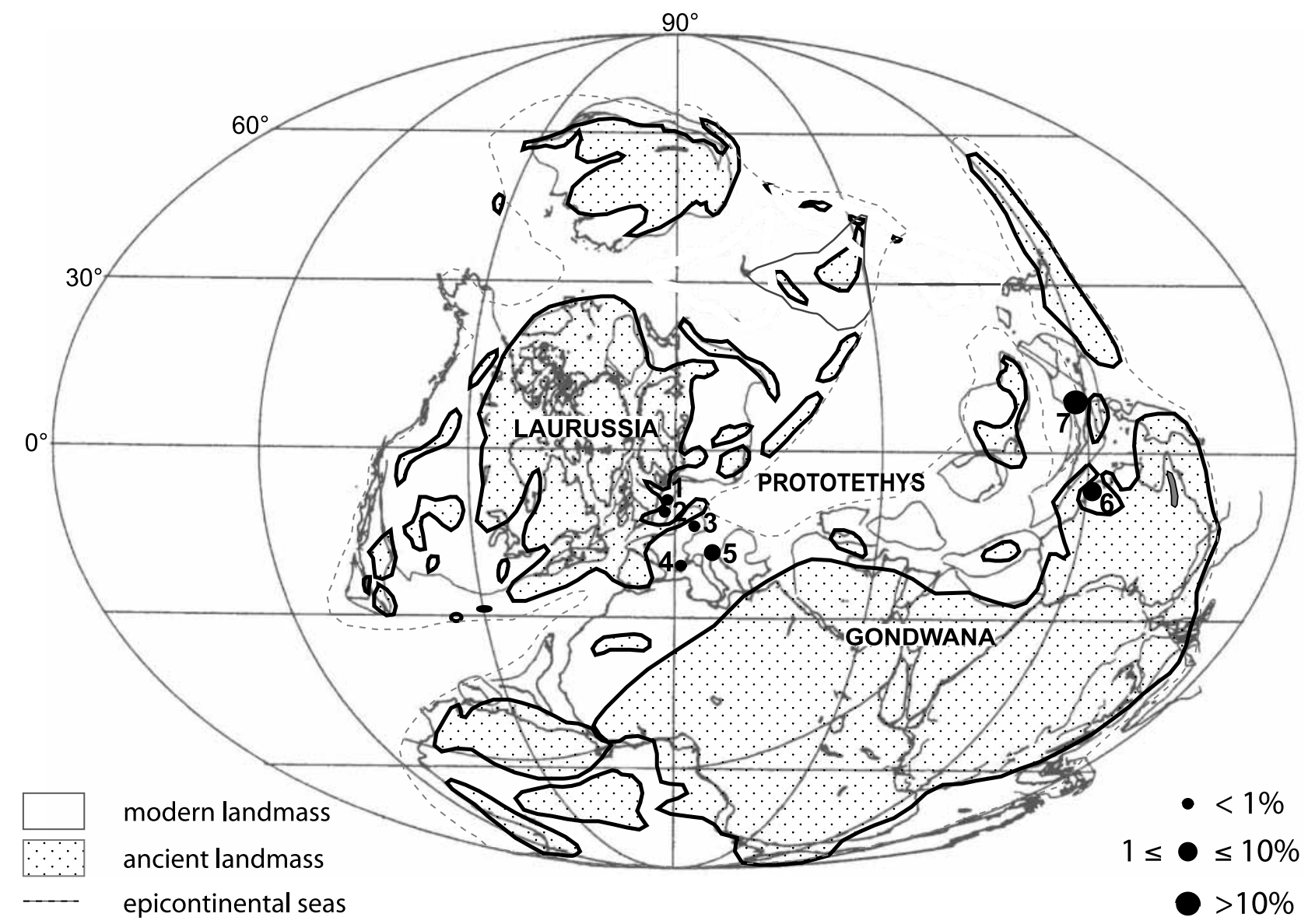

Fig. 1. Palaeogeographical map of the Late Devonian showing the location of the sections considered in the present study (after Scotese \& McKerrow, 1990; Scotese \& Golonka, 1992). 1, Beringhausener Tunnel (Germany); 2, Beul (Germany); 3, Schleiz (Germany); 4, Coumiac Upper Quarry (France); 5, Wolayer Gletcher (Austria); 6, Calix Corner, Horse Spring, Phacopid Gully (Canning Basin, Western Australia); 7, Xom Nha (Vietnam). The size of the circle corresponding to the location of the section is proportional to the percentage of Pa. Palmatolepis linguiformis within Palmatolepis assemblages.

various locations around the Prototethys, i.e. the marine seaway situated between Laurussia to the west and Gondwana to the south and east. A generic approach was chosen, i.e. within a genus but independent of any previous taxonomic descriptions at the species level. This approach was undertaken to ascertain whether a morphometric analysis could yield evidence for the existence of differentiated morphotypes and provide a basis for their palaeobiological interpretation. Furthermore, the spatial scale considered allowed testing if any morphological trends could be associated with some geographical areas and, hence, could be used to track palaeoecological differences.

\section{MATERIAL AND METHODS}

\section{Geographical setting}

Three different palaeogeographical domains (Fig. 1) were documented in this study by sampling nine conodont-bearing outcrops. Laurussian and northwest (NW) Gondwanan samples correspond to latest Frasnian pelagic cephalopod limestones located on outer platforms. Northeast (NE) Gondwanan samples (Vietnam and Australia) are all from limestones situ- ated offshore of a stromatoporoid-bearing reef complex. In Australia, these limestones are located on the marginal slope and basin offshore of the reef.

Outcrops considered in the present study include the following:

- Beul and Beringhausener Tunnel (both from the Rhenish Slates Mountains in Germany) for the Laurussia domain. The levels considered for these two sections are condensed, and the sequence across the Frasnian/Famennian boundary consists of well-bedded, dark-brownish to black limestones considered as an equivalent of the Upper Kellwasser Limestone (Schindler, 1993).

- Schleiz (Germany), Wolayer Gletcher (Austria) and Coumiac (France) for the NW Gondwana margin. These three sections are characterized by extremely condensed beds, typical of a cephalopod limestone facies, deposited on well-oxygenated outer platforms. Levels considered in this study were deposited just before the development of the typical Upper Kellwasser event.

- Xom Nha (Vietnam) and three sections from the Canning Basin (Australia), called Phacopid Gully, Calix Corner and Horse Spring, for the NE Gondwana domain. No evidence of 


\begin{tabular}{|c|c|c|c|c|c|c|c|}
\hline Sections & Abbreviation & Geographical areas & $n$ & $\min$ & $\max$ & mean & SD \\
\hline Beringhausener Tunnel & BHT & Laurussia & 78 & 0.637 & 2.151 & 1.181 & 0.304 \\
\hline Coumiac Upper Quarry & CUQ & NWG & 95 & 0.659 & 3.151 & 1.629 & 0.530 \\
\hline Schleiz & Sch & NWG & 452 & 0.800 & 3.927 & 1.520 & 0.398 \\
\hline Xom Nha & $\mathrm{XN}$ & NEG & 100 & 0.541 & 3.715 & 1.580 & 0.728 \\
\hline Calix Corner & $\mathrm{CC}$ & NEG & 86 & 0.725 & 3.637 & 1.544 & 0.674 \\
\hline
\end{tabular}

Size is estimated by $\mathrm{A}_{0}$, corresponding to the size of the platform outline. $n$, number of elements measured in each section; min, max, minimal (maximal) size value per section; SD, standard deviation; NWG, northwest Gondwana; NEG, northeast Gondwana.

Table 1. Descriptive statistics of the size distribution of the total Palmatolepis assemblage for each section.

lithofacies change can be observed along these NE Gondwana sections. The Xom Nha section is characterized by a carbonate sequence with black limestones (Ta Hoa Phuong, 1998) without any change in the sedimentological conditions at the Frasnian/Famennian boundary. In the Canning Basin, there is no trace of the oxygen-depleted Kellwasser facies (Becker et al., 1991).

All the samples yield biostratigraphical evidence of the time interval within the latest Frasnian. Their correlation is based on the presence of two complementary biostratigraphical markers: the index conodont species of the last zone of the Frasnian, $P a$. Palmatolepis linguiformis, and the last occurrence of the trilobite Palpebralia brecciae (Girard et al., 2005). This time interval corresponds to the early part of the linguiformis Zone in the usage of Sandberg et al. (2002) and to Zone 13b according to the zonation of Klapper et al. (2004). Based on a biochronometric time-scale established with $\mathrm{U} / \mathrm{Pb}$ zircon dating, the isotopic age in the middle of the preceding Late rhenana conodont Zone has been estimated at 377.2 $\pm 3.7 \mathrm{Ma}$ (Kaufmann, 2006). According to this result the time-slice considered here is only a slightly younger (top Late rhenana conodont Zone).

\section{Material}

The rock samples were dissolved in formic acid (10\%) and rinsed through two sieves. The fraction between $100 \mu \mathrm{m}$ and $1 \mathrm{~mm}$ was then picked for all conodont elements. For morphometric analyses, all unbroken platform $\mathrm{Pa}$ elements of the genus Palmatolepis were measured. Determination at the species level is problematic when considering all specimens in a palaeopopulation, particularly for the small sized ('juvenile') specimens. Therefore, species names were not recorded. A separation of the genus into two subgenera, namely $\mathrm{Pa}$. Palmatolepis, including the single species linguiformis in our samples, and secondly $P a$. Manticolepis, which includes all other Frasnian species, was proposed following Müller (1956). Two other Frasnian species, ederi and eureka of Ziegler \& Sandberg (1990), which belong to the subgenus $\mathrm{Pa}$. Palmatolepis in this kind of classification, were not present in our samples. Since the attribution to either Palmatolepis or Manticolepis was unambiguous, this taxonomic information was recorded.

\section{Morphometrics of Palmatolepis platform outlines}

Since conodont elements have bilateral symmetry, both right and left $\mathrm{Pa}$ elements of the genus Palmatolepis are found in an assemblage. As left-right asymmetry of Pa element shape seems to be of minor importance (Renaud \& Girard, 1999), the left elements were subjected to a horizontal mirror transformation and measured as right elements, in order to include right and left elements in the morphometrical analysis so that a larger sample size could be considered. Following the method developed by Renaud \& Girard (1999), the two-dimensional outline of each conodont is automatically digitized using an image analyser (Optimas v. 6.0). For each conodont, 64 points are sampled at equally spaced intervals along the outline, the starting point being defined at the top of the conodont element. From the coordinates, 64 radii are calculated corresponding to the distance of each point to the centre of gravity of the conodont outline. A radial Fourier transform is then applied to this set of 64 radii. The outline is thus expressed as a sum of trigonometric functions of decreasing wavelength, the harmonics. Each harmonic is weighted by two Fourier coefficients, $\mathrm{A}_{n}$ and $\mathrm{B}_{n}$. The set of Fourier coefficients for all harmonics provides a mathematical description of the initial outline.

The zero harmonic, $\mathrm{A}_{0}$, is proportional to the size of each conodont element and is used to standardize all the other Fourier coefficients to retain shape information only.

A characteristic of the Fourier method is that the higher the rank of the harmonic, the more details of the outline it describes. The Fourier coefficients were retained up to the eleventh harmonic for the genus Palmatolepis to filter the measurement error which is expected to increase with the harmonic rank (Renaud, 1999).

From a set of Fourier coefficients, an outline can be reconstructed using an inverse method, providing a visualization of the shape changes between samples or along multivariate axes.

\section{Statistical analyses}

The outline analysis provides two sets of variables. First, the size of the elements can be estimated by the zero harmonic based on the analysis of its outline. Geographical differences in this univariate parameter were investigated using analyses of variance (ANOVA). Since the distribution of the size values could vary between samples, this was addressed by recording minimum, maximum and average values (Table 1).

Each outline of the platform element is described by a set of Fourier coefficients. Analysing this dataset therefore necessitates multivariate statistics. Tests of differences between groups (e.g. geographical areas) were performed using multivariate analyses 


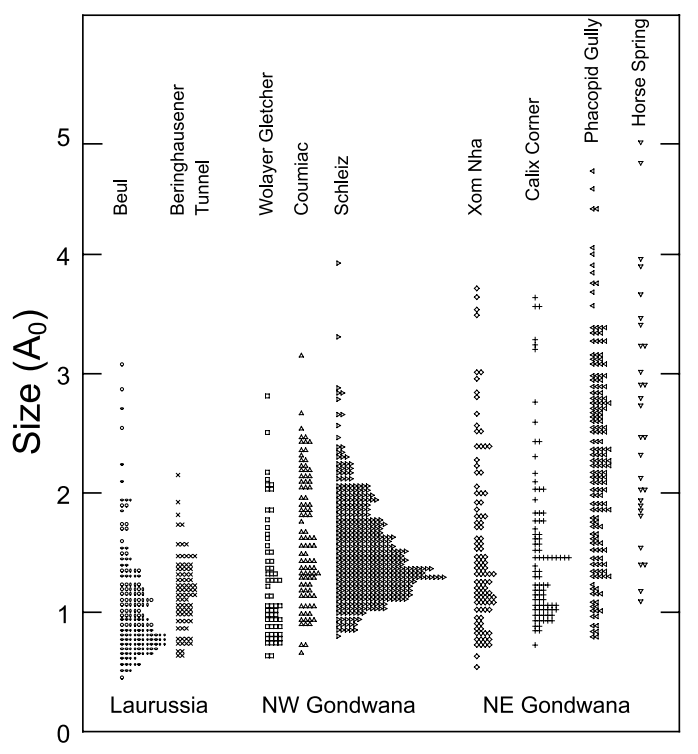

(a)

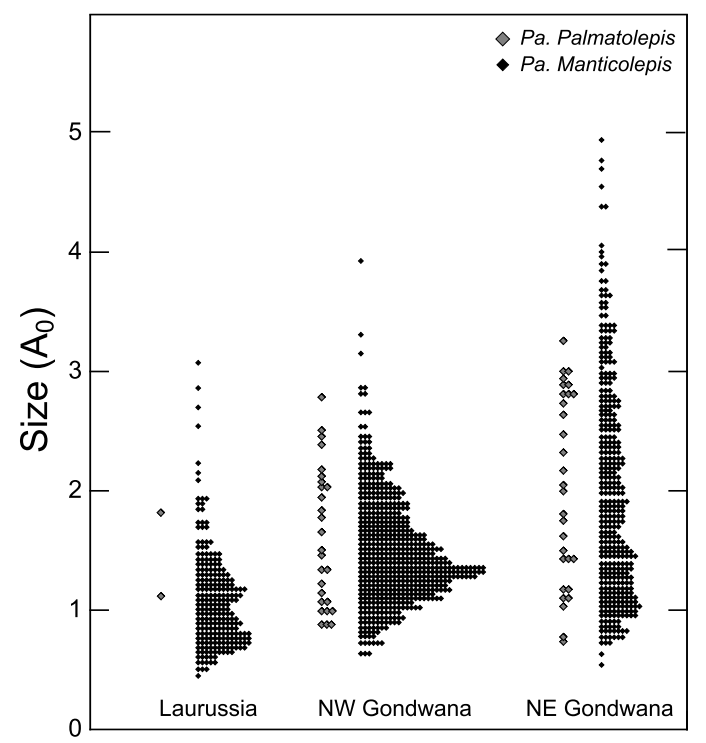

(b)

Fig. 2. Distribution of the size of the Palmatolepis elements. Each dot corresponds to a value. Size is estimated by the zero harmonic of a Fourier analysis of the platform outline. (a) Distribution per section, ordered by geographical region (see Fig. 1). (b) Distribution of Pa. Manticolepis and $\mathrm{Pa}$. Palmatolepis in each geographical region.

of variance (MANOVAs). In order to display the total morphological variance on a few synthetic shape axes, principal component analyses (PCA) were also performed. This method was chosen because it is independent of any a priori taxonomic attribution.

The amount of morphological variation due to growth was investigated by comparing a synthetic shape axis (first principal component, $\mathrm{PC} 1)$ to the size estimator $\left(\mathrm{A}_{0}\right)$. Significant relationships were tested using linear regression between both variables.

In order to assess the importance of this effect in a fully multivariate way and visualize it, the relationship between size and the Fourier coefficients was investigated using multivariate regressions, the dependent variables being the Fourier coefficients (Monteiro, 1999). Using the coefficients of this regression, the outline corresponding to the allometric variation can be reconstructed for any size value.

\section{RESULTS}

Patterns in relative abundance of the two Palmatolepis groups $\mathrm{Pa}$. Manticolepis dominates the $\mathrm{Pa}$. Palmatolepis assemblages in all cases, almost to the exclusion of other elements in some samples, for example, the subgenus $P a$. Palmatolepis is represented by less than one specimen among thousands in a section such as Coumiac CUQ (Girard et al., 2005). The relative abundance of both types has been represented on a palaeogeographical map permitting identification of geographical trends (Fig. 1). The western Prototethys, including both northwestern Gondwanan and Laurussian shelves, is characterized by a very low relative abundance of the subgenus $\mathrm{Pa}$. Palmatolepis, which often contributes less than $1 \%$ of the total Palmatolepis generic assemblage (Fig. 1). In contrast, Pa. Palmatolepis contributes between $4 \%$ and $10 \%$ of the Palmatolepis generic assemblages of the eastern Prototethys.

\section{Variation in size}

The size of the conodont assemblages is significantly different between the three main zones of the Prototethys: Laurussian, NW Gondwanan and NE Gondwanan shelves (ANOVA, $p<0.001)$. Minimal sizes are related to the mesh size of the sieves and hence are not discussed since they should have no palaeobiological relevance. The smallest conodont assemblages (smallest average and maximal values, cf. Table 1) are found on the Laurussian shelf, whereas NE Gondwana sections display the conodont assemblages with the largest size (largest average and maximal sizes) (Fig. 2a). This trend of increasing size from the west to the east of Prototethys is mainly due to an increase in variance of the size distribution. Whereas assemblages of western Prototethys exhibit clear peaks of abundance of small/ intermediate conodonts, assemblages of eastern Prototethys display flattened size distribution characterized by a large variance (Table 1).

The size of subgenera Pa. Palmatolepis and $\mathrm{Pa}$. Manticolepis was compared for the three geographical areas (Fig. 2b). In all three cases, the size of the $P a$. Palmatolepis elements falls into the range of $\mathrm{Pa}$. Manticolepis. There is no size difference between the two groups whatever the geographical area (Laurussia: $p=0.20$, NE Gondwana: $p=0.74$ and NW Gondwana: $p=0.20$ ). The trend of increasing variance in size observed for the whole assemblages from the west to the east of Prototethys is due mainly to differences in $\mathrm{Pa}$. Manticolepis, since this subgenus dominates heavily the assemblages in each area. The same trend seems to be displayed by Pa. Palmatolepis. However, the reduced number of specimens, especially in shelf areas of the 


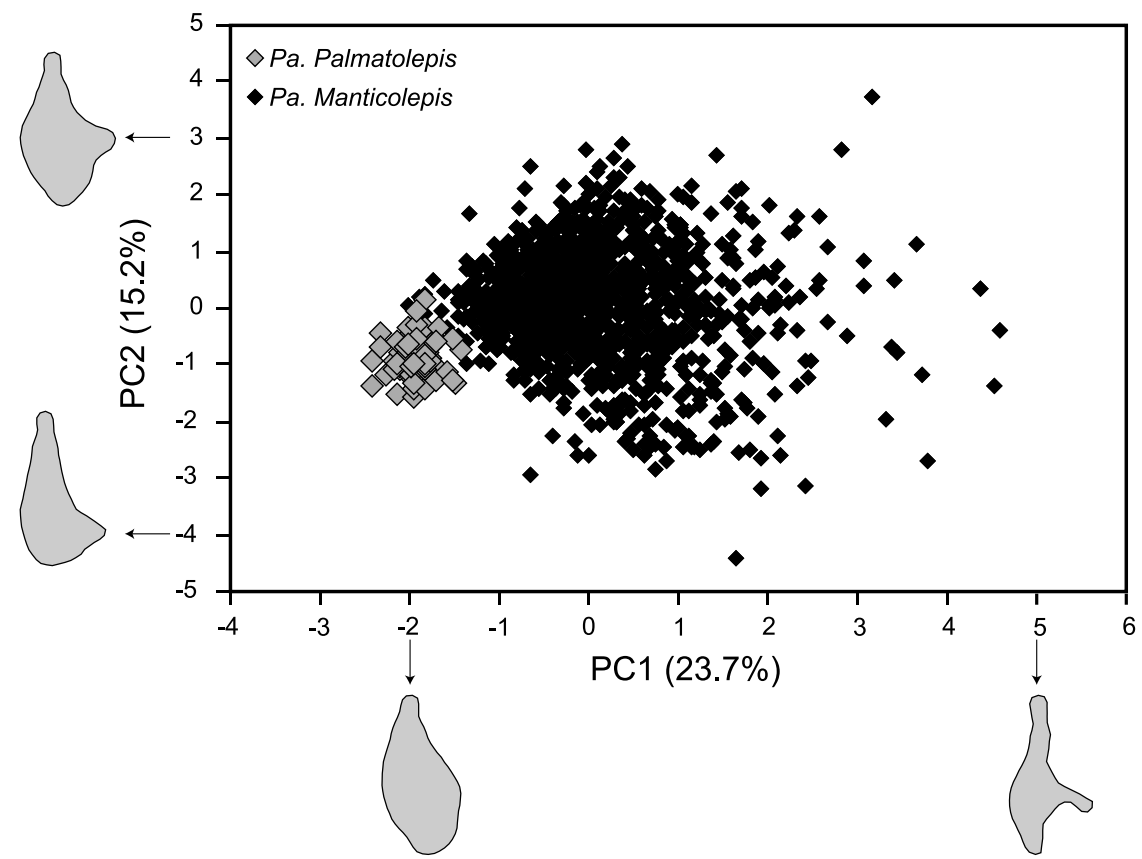

Fig. 3. Morphological variation of Palmatolepis assemblages during the latest Frasnian. Each dot corresponds to an element, plotted on the first two principal components of a PCA performed on the Fourier coefficients of the platform outline. The subgenera Pa. Manticolepis (black symbols) and Pa. Palmatolepis (grey symbols) are distinguished. Reconstructed outlines permit visualization of the shape changes involved along PC1 and PC2. They correspond to $\mathrm{PC} 1=-2$ (left) and $\mathrm{PC} 1=5$ (right), to $\mathrm{PC} 2=-4$ (bottom) and $\mathrm{PC} 2=3$ (top).

northwestern Gondwana margin, hinders any robust conclusion regarding size variations in this subgenus.

Patterns of shape differentiation within total assemblages A first PCA included all elements of the genus Palmatolepis. The first two axes PC1 and PC2 explain $23.7 \%$ and $15.2 \%$ of the total variance, respectively (Fig. 3). This relatively low percentage of variance explained by the first principal plane is due to the large number of variables and specimens, leading to an important diffusion of variance on the subsequent axes. PC1 nevertheless displays the most important shape variance and has been used as a synthetic shape axis. The scatter diagram of the first principal plane (Fig. 3) shows limited evidence of a structure. Along PC1 a cluster of points tends to isolate towards negative values. This cluster includes all Pa. Palmatolepis and few Pa. Manticolepis elements. Towards positive PC1 values, outlines are elongated and characterized by the development of a well-expressed lobe. Such outlines resemble outlines of very typical specimens of the species rhenana. Along PC2, the scatter shows loose ranges without any clear structure. PC2 opposes outlines with a triangular posterior part of the platform and outlines with a short posterior part of the platform, as is the case for the species juntianensis.

When considering $\mathrm{PC} 1$ as a synthetic shape axis, some geographical variation is apparent (Fig. 4). A trend of increasing variance from the west to the east of Prototethys can be observed. This trend is similar to the size pattern and might be due to an allometric shape variation. The difference in shape between Pa. Palmatolepis and Pa. Manticolepis is confirmed (Fig. 4). ANOVAs were performed on PC1 values for each section separately and showed that $\mathrm{Pa}$. Palmatolepis and $\mathrm{Pa}$. Manticolepis are significantly different $(p<0.05)$.
Allometric relationship between size and shape

The similarity of the size and shape patterns of geographical variation suggests that allometric growth could be responsible for both. This hypothesis was tested by plotting the synthetic shape axis PC1 against the size estimator $\mathrm{A}_{0}$ (Fig. 5). This plot demonstrates a clear difference between $\mathrm{Pa}$. Palmatolepis and $P a$. Manticolepis elements. Whereas the former does not exhibit any relationship of $\mathrm{PC} 1$ with size, both variables significantly covary within the latter $\left(r^{2}=0.62, p<0.001\right)$. The important shape variance within the subgenus $P a$. Manticolepis is thus the consequence of a strongly allometric growth pattern. Geographical trends in shape on PC1 (Fig. 4) can thus be interpreted as the result of the trend in size (Fig. 2).

Due to the important component of allometric growth within $P a$. Manticolepis, the morphological difference between the two subgenera increases with size. The small $P a$. Manticolepis are morphologically close to $P a$. Palmatolepis. Thereafter, the larger the $P a$. Manticolepis the more different it is from a $P a$. Palmatolepis-like morphology. This allometric growth of $\mathrm{Pa}$. Manticolepis corresponds to a progressive development of the lateral lobe which becomes more protuberant. The similarity of $\mathrm{Pa}$. Palmatolepis with small Pa. Manticolepis corresponds to a rather rounded outline due to the absence of a well-developed outer lobe.

Growth pattern of the $\mathrm{Pa}$. Manticolepis group

The generic approach indicates that the genus Palmatolepis is composed of two well-differentiated groups: $\mathrm{Pa}$. Manticolepis and $P a$. Palmatolepis elements. This separation is marked especially by different growth patterns. To further characterize the morphological variation within each type, analyses were performed separately on Pa. Manticolepis and Pa. Palmatolepis. 


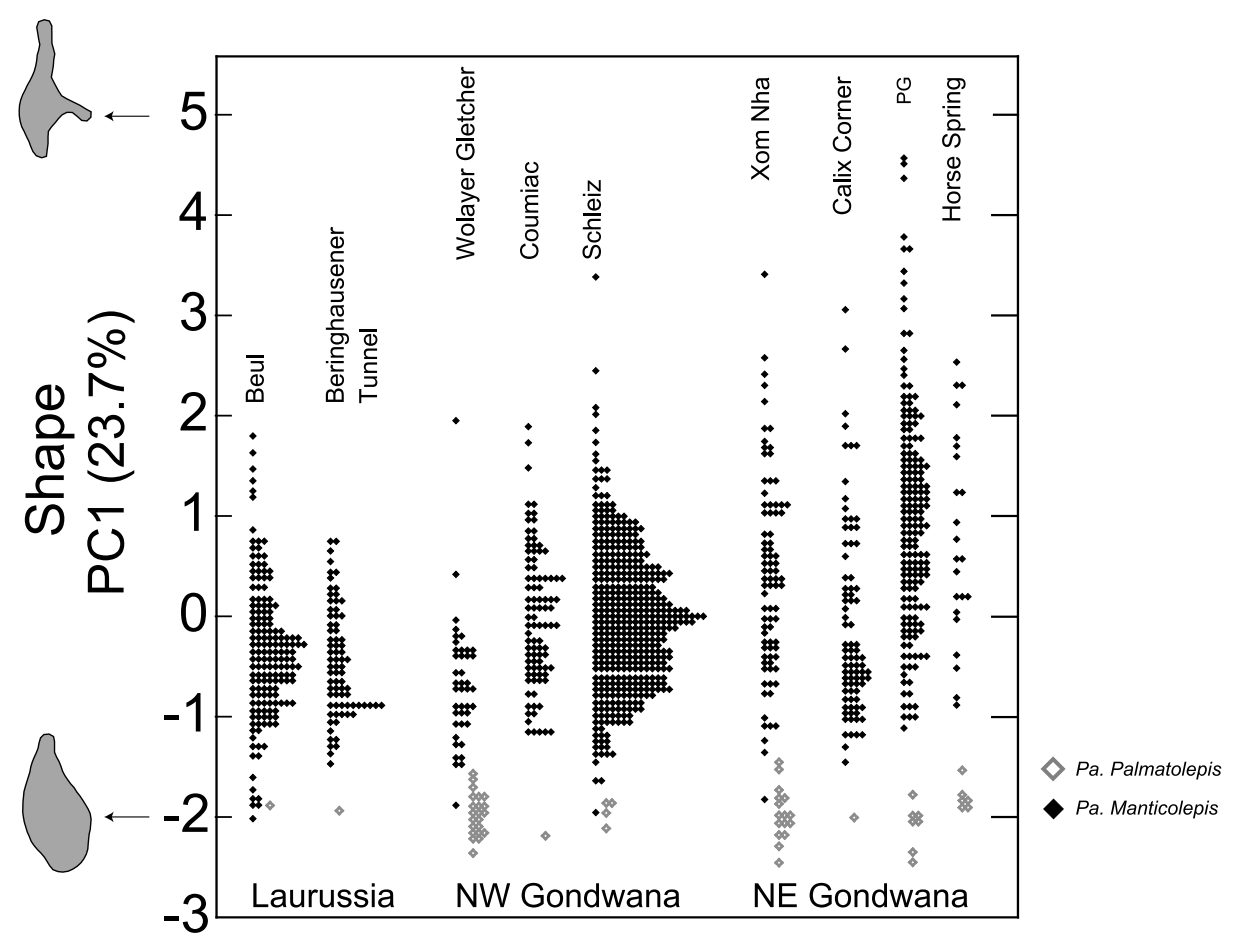

Fig. 4. Distribution of the scores on the first principal component, considered as a synthetic shape axis. Distributions were plotted for each section and, within each section, the subgenera $\mathrm{Pa}$. Manticolepis (black symbols) and Pa. Palmatolepis (grey symbols) were distinguished. Reconstructed outlines permit visualization of the shape changes involved along PC1. They correspond to PC1= -2 (bottom) and PC1=5 (top). PG, Phacopid Gully.

A PCA on Pa. Manticolepis (Fig. 6) does not provide very different results from the analysis on total assemblages but completes the description of the morphological variation. The first principal axis being considered as a synthetic shape axis, it can be compared to the size estimator $\mathrm{A}_{0}$. This confirms the importance of allometric shape variation as shown by the strong correlation between scores on PC1 and size $\left(r^{2}=0.62, p<0.001\right)$ (Fig. 6). The allometric relationship between size and shape is confirmed by a multivariate regression between size $\left(\mathrm{A}_{0}\right)$ and the Fourier coefficients $(p<0.001)$.

The reconstructed outlines corresponding to extreme values along the $\mathrm{PC} 1$ and to different size value using the multivariate regression allow visualization of the shape changes involved in the growth of manticolepid elements (Fig. 6). Growth starts from a rounded shape and the subsequent allometric growth corresponds to the development of a well-expressed lateral lobe.

Possible geographical differences in growth pattern were considered by comparing ontogenetic trajectories (i.e. the relationship between PC1 and size) for each section. For this purpose, the total size range has been split into classes. Threshold values were chosen to equilibrate at the best sample size within each class $\left(0.5<\mathrm{A}_{0}<1.5 ; 1.5<\mathrm{A}_{0}<2.5 ; \mathrm{A}_{0}>2.5\right)$. The mean size of each class was plotted against the corresponding mean value on PC1. The ontogenetic trajectories obtained for each section are very similar (Fig. 6) and further show that geographical difference in size and shape variance are not related to a change in allometric pattern.

Growth pattern of the Pa. Palmatolepis group

The generic analysis suggested an isometric growth for $P a$. Palmatolepis (Fig. 5). However, an analysis focused on this group alone demonstrates a significant relation between size $\left(\mathrm{A}_{0}\right)$ and shape (PC1) $\left(r^{2}=0.65, p<0.001\right)$ (Fig. 7). Hence, the growth of this group is not only isometric but also displays an allometric component, confirmed by the multivariate regression $(p<0.001)$. The allometric pattern is independent of the one in Pa. Manticolepis since it is not displayed on the same multivariate axis, when the two groups are considered together (Fig. 5).

Reconstructed outlines of values along $\mathrm{PCl}$ and using the multivariate regression confirm that allometric growth involves only slight changes in Pa. Palmatolepis compared to the important changes during growth characterizing $P a$. Manticolepis. The larger the Pa. Palmatolepis-like element, the more arched is the platform, without becoming more pronounced.

As for Pa. Manticolepis, growth patterns were compared among geographical locations. This comparison, however, was limited by the reduced number of $P a$. Palmatolepis elements in many sections. Only Wolayer Gletcher, sampling the NW Gondwanan shelf, and Xom Nha, located at the east of Prototethys, contained enough specimens to allow such an analysis. For these two sections, the total size range was split into size classes $\left(0.5<\mathrm{A}_{0}<1 ; 1<\mathrm{A}_{0}<1.5 ; 1.5<\mathrm{A}_{0}<2 ; 2<\mathrm{A}_{0}<2.5 ; \mathrm{A}_{0}>2.5\right)$ (Fig. 7). Ontogenetic trajectories obtained for west and east Prototethys are very close to each other, suggesting that $P a$. Palmatolepis displays no geographical differences in growth pattern.

\section{DISCUSSION}

The 'generic' morphometric approach

Numerous species have been described within the genus Palmatolepis, for example during the latest Frasnian interval, more 


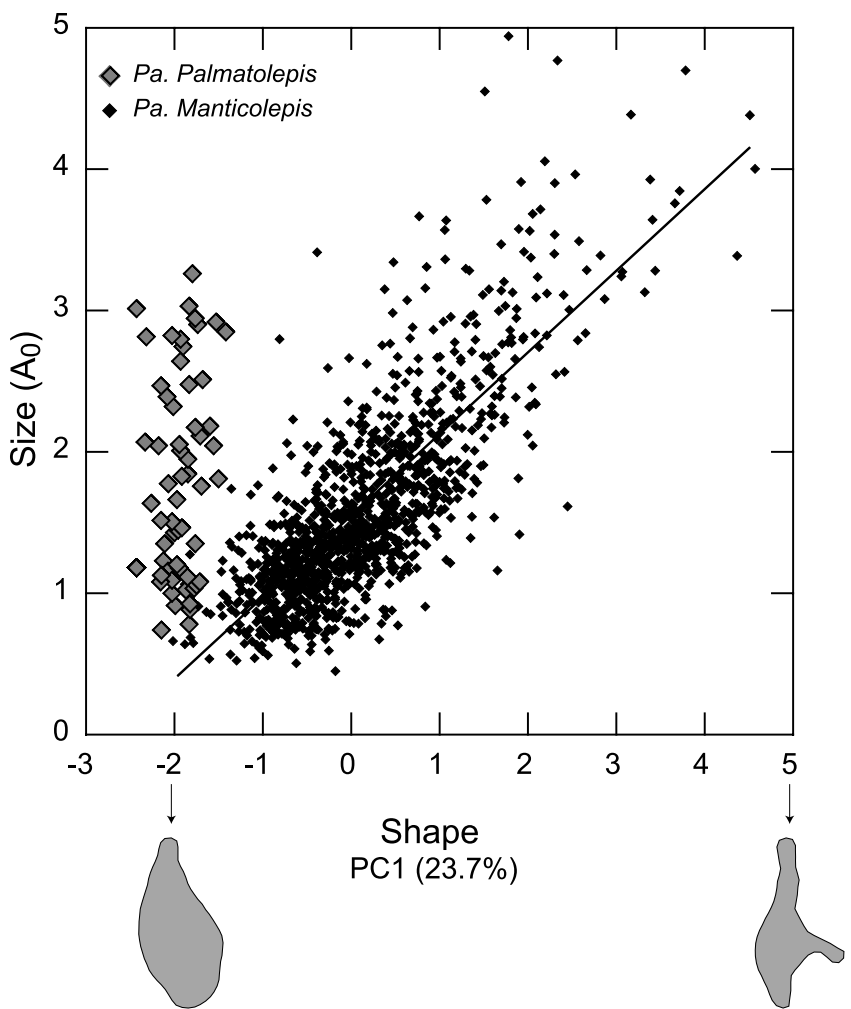

Fig. 5. Relationship between size and shape within the genus Palmatolepis. The shape is estimated by scores on the first principal component of a PCA on total Palmatolepis assemblages. The size of each element is estimated by $\mathrm{A}_{0}$. The solid line corresponds to a linear regression of $\mathrm{A}_{0}$ vs. PC1 for $\mathrm{Pa}$. Manticolepis only. Reconstructed outlines permit visualization of the shape changes involved along PC1. They correspond to $\mathrm{PC} 1=-2$ (left) and $\mathrm{PC} 1=5$ (right). than 15 taxonomic species were proposed (Ziegler \& Sandberg, 1990; Klapper \& Foster, 1993). In the time-slice studied in this paper, at the base of the linguiformis Zone five species can be found following the Late Devonian standard zonation of Ziegler \& Sandberg (1990): Pa. linguiformis, Pa. rhenana, Pa. subrecta, $P a$. rotunda and Pa. gigas. Alternatively, only four species can be recognized following Klapper \& Foster (1993): Pa. linguiformis, Pa. rhenana, Pa. winchelli and Pa. bogartensis, the two latter being respectively junior synonyms of $P a$. subrecta and $P a$. rotunda in the terminology of Ziegler \& Sandberg (1990).

In both cases, these described species do not include all the Palmatolepis specimens within a given sample. Small elements and some undetermined specimens are arbitrary included in a species (Sandberg et al., 1988), the described species being generally based on large, 'mature' specimens. In numerous papers, more than $90 \%$ of the Palmatolepis Pa elements remain undetermined (Schülke, 1995; Morrow, 2000; Girard et al., 2004). This large amount of undetermined specimens in an assemblage, together with the limited differentiation within $P a$. Manticolepis emerging from the morphometric analysis, questions the validity of the taxonomic species as biologically relevant entities.

These facts, however, are based on a single element $(\mathrm{Pa})$ of a complex apparatus, and multi-element approaches may help to resolve the taxonomic uncertainty. A major limit to this approach is that only a few apparatuses of Palmatolepis have been found in place (Lange, 1968; Puchkov et al., 1981). They allow associating different types of elements $(\mathrm{Pa}, \mathrm{Pb}, \mathrm{M}$ and $\mathrm{S})$ at the generic level but not at a lower taxonomic level.

The multi-element approach, as usually applied for taxonomic purposes, therefore relies on association of the different types of elements based on their relative proportion in the assemblages, as well as some morphological similarities, and not on direct observations.

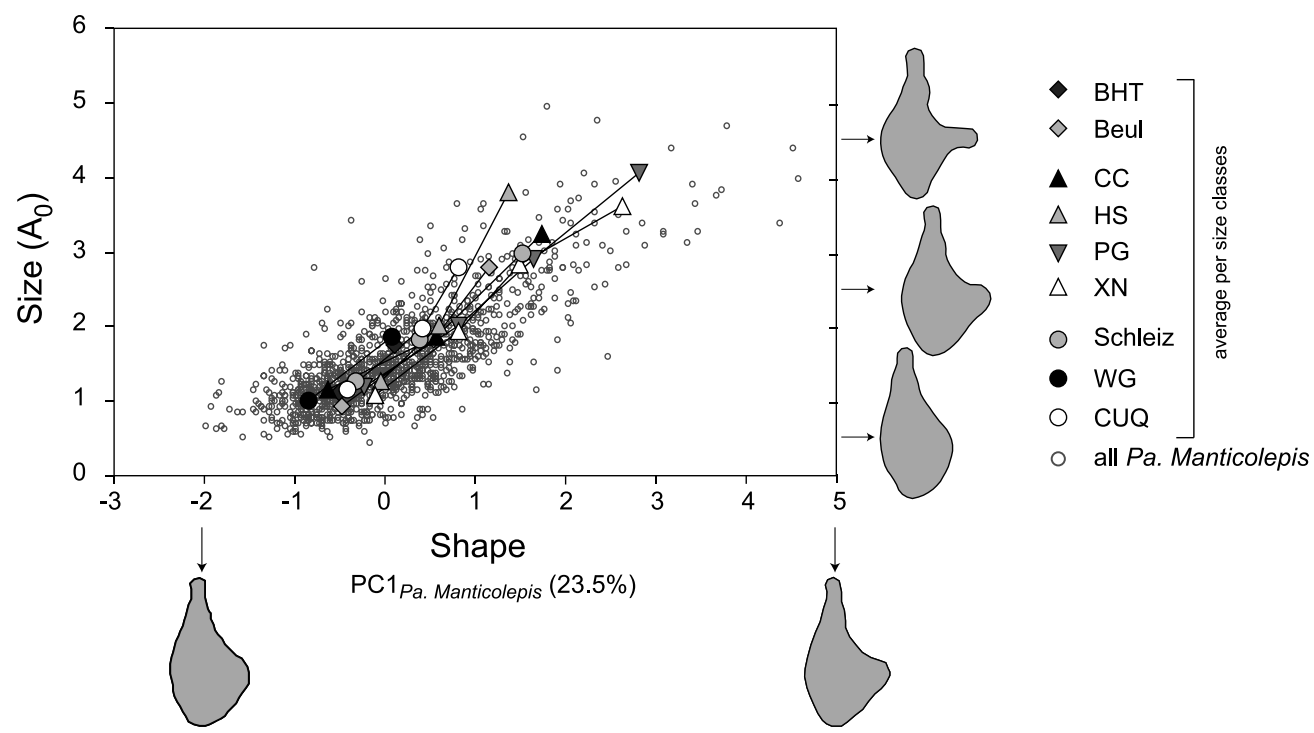

Fig. 6. Relationship between size and shape within Pa. Manticolepis. Size is estimated by $\mathrm{A}_{0}$, shape by scores on PC1 (PCA on Pa. Manticolepis alone). Reconstructed outlines visualize the allometric shape changes. Along the horizontal axis, outlines correspond to extreme values along PC1 $(\mathrm{PC} 1=-2$ (left) and $\mathrm{PC} 1=5$ (right). Along the vertical axis, outlines are based on the multivariate regression of the Fourier coefficients on size. They illustrate the allometric shape change from size values of 0.5, 2.5 and 4.5. Each dot corresponds to an element. To visualize the growth pattern for each section, the total size range has been split into classes (see text) and average size and shape values were plotted for each class (abbreviations for the sections are at the right of the graph, cf. Table 1). The large symbols correspond to the mean value of the size classes for each section, linked by a solid line. 


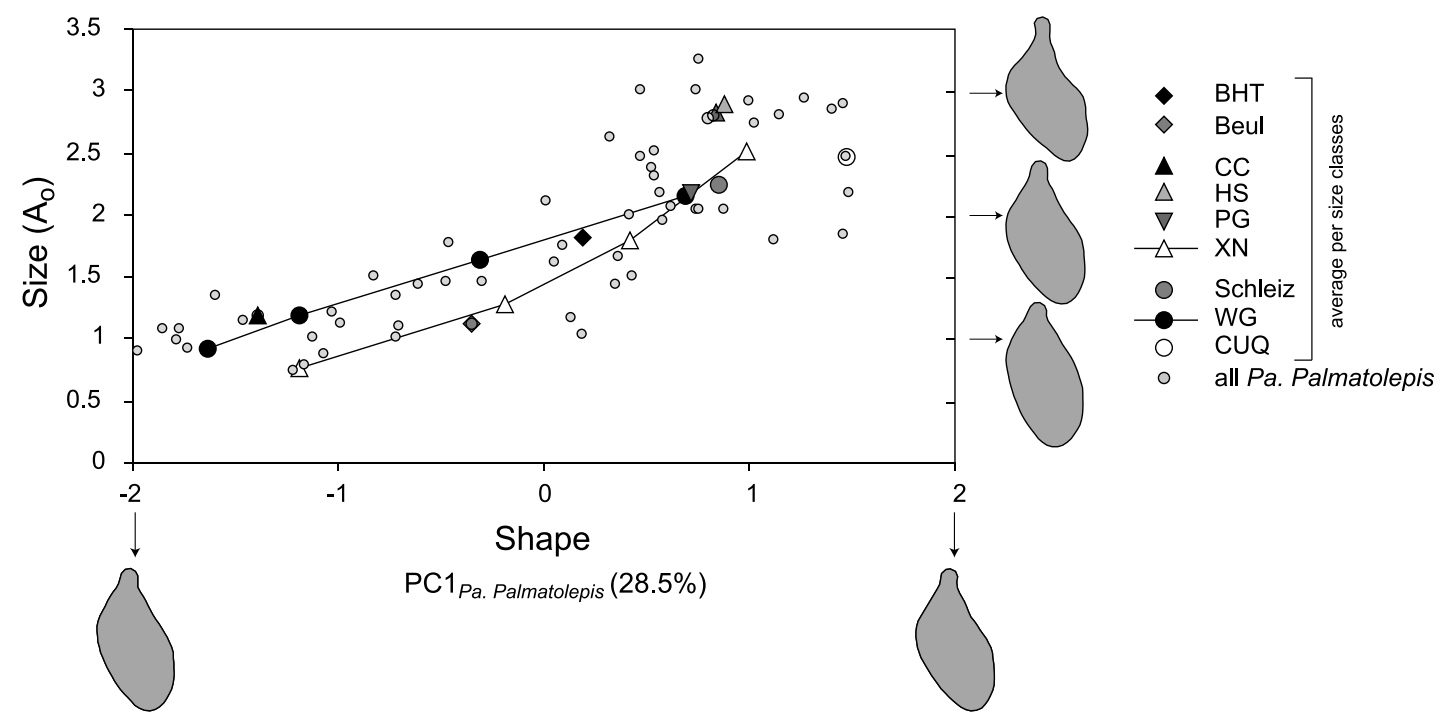

Fig. 7. Relationship between size and shape within the subgenus $P a$. Palmatolepis. Size is estimated by $\mathrm{A}_{0}$, shape by scores on PC1 (PCA on Pa. Palmatolepis alone). Reconstructed outlines visualize the allometric shape changes. Along the horizontal axis, outlines correspond to extreme values along PC1 ( $\mathrm{PCl}=-2$ (left) and $\mathrm{PCl}=2$ (right). Along the vertical axis, outlines are based on the multivariate regression of the Fourier coefficients on size. They illustrate the allometric shape change from size values of 1,2 and 3 . Each dot corresponds to an element. To visualize the growth pattern, the total size range has been split into classes (see text) and average size and shape values were plotted for each class (abbreviations for the sections are at the right of the graph, cf. Table 1). Only the sections of XN and WG included enough Pa. Palmatolepis Pa elements to draw an ontogenetic trajectory (represented by the solid line linking the average values of successive size classes).

Such a multi-element approach has been applied in the Late Devonian. Some workers used a qualitative method to associate elements (Klapper \& Philip, 1971), whereas others based the association between element types on quantitative proportions (van den Boogard \& Kuhry, 1979). However, recently von Bitter \& Purnell (2005) concluded that despite employing a quantitative approach, the use of ratios of occurrence of element types to recognize apparatuses is suspect. In the Silurian Ozarkodina excavata, the proportions of element types inferred from assemblages of isolated elements and observed on entire apparatuses are different. The discrepancy is likely due to post-mortem biases, such as element fragmentation during sediment compaction and diagenesis.

The multi-element approach may be inappropriate for addressing the question of the relevant palaeobiological entities to be considered in the Late Devonian Palmatolepis - despite appearing attractive - because it is based on the complete apparatus. The use of a morphometric method based on a well-preserved and morphologically variable element seems thus the best method so far. The Pa element was considered based on these criteria, but this view has been challenged by Dzik (2002), who suggested the use of the $\mathrm{M}$ element. His arguments are that a biometric analysis of the $\mathrm{Pa}$ elements failed to reveal any taxonomic structure because of the high variation in this element, and that the less variable $\mathrm{M}$ element would be more adequate. This conclusion, unfortunately, is not based on any biometric analysis and seems thus arbitrary.

Furthermore, a pioneering generic morphometric analysis on the NW Gondwanan sections has shown that taxonomically identified elements usually correspond to extreme specimens of a homogeneous scatter (Girard et al., 2004). More strikingly, Palmatolepis assemblages exhibited morphometric variations through time during the Late Frasnian. This could not be attributed to a change in the specific composition; rather the different taxonomic species varied in the same way (Renaud \& Girard, 1999; Girard et al., 2004). Despite thinking that the Palmatolepis apparatuses consist exclusively of Palmatolepiforms, Fåhraeus (1982) suggested a close biological relationship among Palmatolepis-like elements based on the morphological likeness among elements and the regional co-occurrences of the morphotypes. All these results suggest that Palmatolepis assemblages can be considered as a complex of closely related species sharing common reactions to environmental variations.

This last point is in agreement with the proposition of Ziegler \& Sandberg (1990) that the progenitor of all Famennian Palmatolepis species, $P$ a . praetriangularis, evolved 'from a field of transition among three closely related species': Pa. subrecta, Pa. rotunda and their ancestor Pa. hassi. Pa. hassi is also supposed to be the ancestor of an another Palmatolepis sub-branch, including $P a$. rhenana and $P a$. linguiformis, proposed by the same authors.

The present study does not consider variations in Palmatolepis through time but rather through space, during the time interval of the latest Frasnian. In this dataset, Palmatolepis no longer appears as one homogeneous biological group but composed of two clearly distinct entities. These two groups match the definition of two of the three subgenera proposed by Müller (1956). Hence, among many other phylogenetic hypotheses for the genus Palmatolepis (Sweet, 1988; Dzik, 2002), these results clearly support a dichotomy between the subgenus Pa. Palmatolepis (including the species linguiformis), and the subgenus $P a$. Manticolepis, during the latest Frasnian. Conodonts of the subgenus Pa. Palmatolepis have also been described from the Famennian (Müller, 1956; Clark et al., 1981; Sweet, 1988) but the species linguiformis is proposed to constitute the only valid representative of the subgenus for our latest Frasnian specimens. 
As the present analysis is focused on the latest Frasnian, it does not allow investigation of the relationship between the Frasnian and the Famennian linguiformis-like conodonts. The differentiation of the two subgenera in the latest Frasnian assemblages was not identified in previous studies (e.g. Girard et al., 2004) because they were focused on sections of the NW Gondwanan shelf where $P a$. $P a$. linguiformis is extremely rare. Based on the results of the present study, $\mathrm{Pa}$. Manticolepis can be considered as a homogeneous group during the latest Frasnian.

Based on this interpretation, some further questions arise: what pattern of morphological differentiation separates the two clades? Can the morphological differences be related to any palaeoecological characteristics? Finally, are the two clades characterized by different palaeoenvironmental preferences?

\section{Phylogenetic differences between Pa. Manticolepis and Pa.}

\section{Palmatolepis as a divergence of their ontogenetic trajectories} Conodont elements grew by accretion of growth lamellae around a nucleus and these lamellae are not of equivalent width in all parts of the elements, due to the direction of preferential growth (Gross, 1960). The final shape of an element is thus determined by the initial shape of the nucleus, the pattern of anisometric growth and the number of lamellae, supposedly proportional to the age of the animal (Zhuravlev, 1995). Assessing the relationship between age and shape of an element would thus require one to count the number of lamellae to estimate the 'age' of the element, and to compare the shape of the successive lamellae. Such an approach has remained difficult up to now due to methodological limitations. Hence, the size of each element can be taken as a proxy of the conodont 'age' to analyse ontogenetic processes (Donoghue \& Purnell, 1999) and the sizeshape relationship on the whole assemblage (or within each taxon) provides an estimate of the ontogenetic trajectory.

This study evidenced that Pa. Manticolepis and Pa. Palmatolepis are separated by the shape of their Pa element. Given the mode of growth of the elements, this shape difference may be due to various processes: phylogenetic differences of the nucleus persisting constantly and independently of the growth in each clade; heterochronic processes related to shift in the ontogenic trajectories of the two clades; or independent ontogenetic trajectories. In order to identify the evolutionary basis of the shape difference between the two clades, their growth patterns should be analysed and compared.

A global analysis of Palmatolepis $\mathrm{Pa}$ elements actually showed that two of these processes are involved in the $P a$. Manticolepis-Pa. Palmatolepis differentiation. First, a slight difference between the smallest elements of each group suggests that the nuclei might differ in shape. Results suggest that this difference is of limited importance.

Secondly, the shape difference increases during ontogeny due to a strong allometric component in the growth of $\mathrm{Pa}$. Manticolepis. Small specimens of both taxa share a round morphology with a small platform that develops later during the ontogeny of $\mathrm{Pa}$. Manticolepis, leading to extreme shape for the largest specimens. Focusing on Pa. Palmatolepis alone shows that an allometric component also exists in this taxon, although this is much more limited than within $\mathrm{Pa}$. Manticolepis. This allometric component corresponds to a direction of shape change independent of the one characterizing $P a$. Manticolepis, since they are expressed on different multivariate axes. Hence, the shape difference between the two groups is supported mostly by ontogenetic differences unrelated to any heterochronic processes: Pa. Palmatolepis displays a rather isometric growth in contrast to $P a$. Manticolepis, and the allometric components in the ontogeny of both taxa are independent. Pa. Palmatolepis linguiformis is a taxon with a very limited temporal range (Sandberg et al., 2002; Girard et al., 2005), hence, the difference between $\mathrm{Pa}$. Manticolepis and $\mathrm{Pa}$. Palmatolepis probably built up rapidly.

Ontogenetic trajectories are known to be very evolvable (Raff, 1996). A recent dichotomy between both groups may have led to a significant change in a short time because ontogenetic trajectories were involved. On the contrary, the shape of the nucleus, very close in both taxa, may be a shared inheritance from the ancestor.

\section{Geographical distribution of $\boldsymbol{P a}$. Manticolepis and $\boldsymbol{P a}$. Palmatolepis subgenera}

The generic morphometric approach permitted the identification of what should be considered as evolutionary units for palaeobiological interpretation. Based on this interpretation, the possible causes of variation within each 'taxon' can be investigated.

Comparison between $\mathrm{Pa}$. Manticolepis and $\mathrm{Pa}$. Palmatolepis at different locations around the Late Devonian Prototethys demonstrated only a limited morphological variation within each group. This suggests that an efficient mixing throughout Prototethys allowed for buffering of any local differentiation. This is in agreement with data on eustatic variations, suggesting that overall the Devonian was a period of sea-level highstand, with a maximum during the Late Frasnian (Johnson et al., 1985). Such high sea-level conditions favoured large-scale mixing of pelagic faunas, as shown by the high degree of faunal cosmopolitanism at that time (Klapper \& Johnson, 1980). Conodonts, interpreted as pelagic animals, also display this trend (Ziegler \& Sandberg, 1990) and the results are in agreement with these general observations.

However, the morphometric analysis demonstrated some finer variations within each group. These geographical variations correspond to a size and shape pattern, both being related by allometric constraints. Rather than a differentiation of size and shape at various locations, this pattern corresponds to an increasing size and shape variance from the west to the east in Prototethys. This pattern is especially clear for $\mathrm{Pa}$. Manticolepis but might be exhibited in the same way by $\mathrm{Pa}$. Palmatolepis.

Western $P a$. Manticolepis assemblages are composed of relatively small elements, with a clear peak at intermediate-small sizes, whereas eastern assemblages do not display a clear mode but rather a flattened distribution, with a large variance due to the occurrence of large elements. Since this feature can be recognized in several sections in each region, it is unlikely to be the result of depositional bias. Assuming that the size of the element can be a proxy for the body size of the animal (Purnell, 1994), it rather suggests that populations experienced locally different environmental conditions leading to different life history strategies. A larger size can correspond to a faster growth rate and/or to a longer life span. Given the scarcity of data on conodont palaeobiology, it is difficult to unravel the significance of the size changes observed. However, the fact that conodonts 
are more abundant in western parts of Prototethys, together with the clear mode in size distribution in western assemblages, may suggest that in these regions, palaeopopulations adopted a strategy of early reproduction, with a lot of offspring, whereas eastern populations would have been longer lived.

\section{Allometric growth patterns related to ecological differences?}

The element was part of a complex feeding apparatus. As such, it was probably subjected to selective pressure related to its function. The feeding apparatus of the conodont animal was a complex structure composed of different kinds of elements. Within this apparatus, it has been suggested that the Pa elements, located posteriorly, cut and crushed the food (Purnell \& von Bitter, 1992; Purnell, 1994). Based on measurements of $\mathrm{Pa}$ elements of Carboniferous conodonts, Purnell (1994) concluded that the mode of growth of conodont elements is incompatible with a filtering function of the apparatus but consistent with a grasping, food-processing function. He proposed an analogy of the platform of $\mathrm{Pa}$ elements with the surface area of mammal teeth. Given the 3D shape of the $\mathrm{Pa}$ element of the genus Palmatolepis, however, occlusal contact between right and left parts seems unlikely, due to the fact that the greater part of the element surface cannot have been in direct contact with the opposing element (Nicoll, 1987).

Despite the obvious limitations to a functional interpretation of the elements, the hypothesis that a different shape should be related to a different function, i.e. feeding behaviours, still appears to be valid, since it is generally the case in various feeding apparatuses (Streelman et al., 2003; Ward-Campbell et al., 2005). Such differences may even occur within a taxon following ontogenetic changes (Armstrong \& Smith, 2001). They identified two phases of growth in conodonts and interpreted the morphological differences between the small 'juvenile' elements and the large 'adult' ones as evidence for a different function related to different modes of life or feeding strategies. According to such an interpretation, the shape differences observed between $\mathrm{Pa}$. Manticolepis and Pa. Palmatolepis could be related to ecological differences. The overall similar shape of small-sized elements of both taxa could, together with a phylogenetic relationship, indicate a similar mode of feeding. Since $P a$. Palmatolepis elements remain similar overall during growth, the animals would have retained the 'juvenile' feeding behaviour during their later life. In contrast, the ontogenetic morphological changes observed for $\mathrm{Pa}$. Manticolepis might be related to a change in the feeding habits of the animal.

The change in diet might have been associated with other changes in the life habits of the conodont animal, such as the depth of habitat, which might have changed the feeding resources available for the animal during the different stages of its growth. More knowledge about food chain structure in the Late Devonian, as well as new data on possible functioning of the feeding apparatus of the conodonts, is necessary to make such reasoning less hypothetical. Even the possible organisms conodonts were feeding on currently remain unknown.

\section{Palaeoenvironmental preferences of $\mathrm{Pa}$. Manticolepis and $\mathrm{Pa}$. Palmatolepis subgenera}

The different shape and growth pattern of the feeding elements of Pa. Manticolepis and Pa. Palmatolepis suggest that these long extinct animals might have been characterized by ecological differences in their diet. Differences in feeding behaviour were probably associated with differing success in various habitats.

The relative preferences of each conodont type regarding habitat characteristics may be deciphered by analysing their abundance in various palaeoenvironmental settings (e.g. Renaud et al., 2002). While almost absent within assemblages of the western margin of Prototethys, $\mathrm{Pa}$. Palmatolepis comprises a significant part of the eastern assemblages (up to $10 \%$ ). If the environmental characteristics of the western vs. eastern Prototethys can be identified, it could hint at the preferences of Pa. Manticolepis versus Pa. Palmatolepis.

The presence of stromatoporoid reefs close to the studied samples during the latest Frasnian in Vietnam and Australia provides some evidence of palaeoenvironmental differences between the NE Gondwanan and the NW Gondwanan/Laurussian margins (Copper, 2002). The Australian conodont faunas are not found directly in the stromatoporoid reefs, but offshore of the reef complex; however, the proximity of the reef can explain environmental differences. The debris-flow ramp where the Australian conodonts were sampled is evidence of an input of allochthonous material coming from the reef by gravitational transport. The input of material and nutrients due to the close proximity of reefal environments should have been the first environmental indicator of offshore conditions in Australia. Furthermore, in modern oceans the presence of symbiontbearing reefs reveals particular environmental conditions. Low levels of primary productivity (PP) are one of the prerequisites, since high PP causes high turbidity levels, in turn depriving symbionts of their required high levels of light. High turbidity levels can also be the result of a high sediment input. Such conditions were probably very unfavourable for stromatoporoid reefs with low rates of vertical growth. The presence of stromatoporoid reefs on the eastern shelves of Prototethys could thus indicate oligotrophic environments, whereas western shelves would have been characterized by higher levels of nutrient availability and PP.

Although remaining highly speculative, such environmental differences could support the palaeoecological interpretation of the two Palmatolepis subgenera. Pa. Manticolepis appears as a generalist taxon with overall success. Nevertheless, the size structure of assemblages suggests that conditions on the western Prototethys margin were able to sustain abundant $\mathrm{Pa}$. Manticolepis populations dominated by small-sized specimens. On the contrary, the $\mathrm{Pa}$. Palmatolepis subgenus appears to have been a specialist taxon with significant populations restricted to the eastern part of the seaway.

\section{CONCLUSIONS}

1. The 'generic' morphometric approach permitted favouring of one phylogenetic hypothesis among many others proposed for Palmatolepis elements of the Late Frasnian. Two morphological groups can be distinguished, corresponding to two previously proposed subgenera: $P$ a. Manticolepis and Pa. Palmatolepis, the latter including the species linguiformis.

2. The two groups of Palmatolepis are characterized by different relationships between size and shape during growth. $\mathrm{Pa}$. Manticolepis growth is strongly allometric, starting from 
round small elements with a small lobe to large elements with a well-developed platform. In contrast, $P a$. Palmatolepis is characterized by a more isometric ontogenetic trajectory, its Pa element remaining approximately the same at any size. This 'taxon' is short lived and characterizes the latest Frasnian. Its fast divergence from the ancestral Palmatolepis stock might have been realized by a shift in the direction of preferential accretion during element growth, whereas the shape of the nucleus remained unchanged.

3. Pa elements are part of a feeding apparatus. Differences in the shape of the elements might thus be related to differences in feeding behaviour. Accordingly, the changes in shape during the growth of $\mathrm{Pa}$. Manticolepis $\mathrm{Pa}$ elements might correspond to a change in diet, whereas $\mathrm{Pa}$. Palmatolepis would conserve the same feeding behaviour through all its life.

4. Based on relative abundance of the subgenera Pa. Manticolepis and $\mathrm{Pa}$. Palmatolepis, it can be suggested that the preferred conditions of $\mathrm{Pa}$. Palmatolepis were offshore off reefs, whereas $\mathrm{Pa}$. Manticolepis seems to have been more of a generalist. Within $P a$. Manticolepis, changes in size distribution from west to east in Prototethys suggest that the different palaeoenvironmental conditions selected for different life history traits in the conodont populations.

These interpretations remain highly speculative given the scarcity of information on conodont palaeobiology. Rather than bringing definitive answers, the present study raises many questions. To go beyond this present step, the possible relationship linking the shape of the elements and their function with the possible prey consumed should be better understood. Analysis of fine morphological variations in conodont elements would then enrich our understanding of Late Devonian ecosystems.

\section{ACKNOWLEDGEMENTS}

The authors thank Patrick R. Racheboeuf for collecting samples in the Central Vietnam and Dieter Korn for help in the field. Daniela Schmidt is thanked for commenting on an earlier version of the manuscript. Despite the fact that Gilbert Klapper does not agree on the interpretation of the 'generic approach', the authors are grateful to him for both careful reading of a previous version of this manuscript and a good review. A helpful review by Phil Donoghue is acknowledged. Contribution ISEM (2006-077) and UMR5125-07.008.

\section{Manuscript received 9 February 2006 Manuscript accepted 8 November 2006}

\section{REFERENCES}

Armstrong, H.A. \& Smith, C.J. 2001. Growth patterns in euconodont crown enamel: implications for life history and mode-of-life reconstruction in the earliest vertebrates. Proceedings of the Royal Society of London, Series B, 268: 815-820.

Becker, R.T., House, M.R., Kirchgasser, W.T. \& Playford, P.E. 1991. Sedimentary and faunal changes across the F/F Boundary in the Canning Basin of western Australia. Historical Biology, 5: 183-196.

Boogard, van den, M. \& Kuhry, B. 1979. Statistical reconstruction of the Palmatolepis apparatus (Late Devonian conodontophorids) at the generic, subgeneric, and specific level. Scripta Geologica, 49: 1-57.

Clark, D.L., Sweet, W.C., Bergström, S.M., et al. 1981. Conodonta. Treatise on invertebrate Paleontology, Part W (Miscellanea). Suppl. 2. Geological Society of America and University of Kansas, 202pp.
Cooper, A. 2005. Using ancient DNA to evaluate the origins of large mammal phylogeography: The view from Beringia. 9th International Mammalogical Congress, Sapporo, Japan: 181-182.

Copper, P. 2002. Reef development at the Frasnian/Famennian mass extinction boundary. Palaeogeography, Palaeoclimatology, Palaeoecology, 181: 27-65.

Darling, K., Wade, C., Stewart, I., Kroon, D., Dingle, R. \& Brown, A. 2000. Molecular evidence for genetic mixing of Arctic and Antarctic subpolar populations of planktonic foraminifers. Nature, 405: 43-47.

de Vargas, C., Norris, R., Zaninetti, L., Gibb, S.W. \& Pawlowski, J. 1999. Molecular evidence of cryptic speciation in planktonic foraminifers and their relation to oceanic provinces. Proceedings of the National Academy of Sciences, USA, 96: 2864-2868.

de Vargas, C., Renaud, S., Hilbrecht, H. \& Pawlowski, J. 2001. Pleistocene adaptative radiation in Globorotalia truncatulinoides: genetic, morphologic, and environmental evidence. Paleobiology, 27: 104-125.

Donoghue, P.C.J. 2001. Conodonts meet cladistics: recovering relationships and assessing the completeness of the conodont fossil record. Palaeontology, 44: 65-93.

Donoghue, P.C.J. \& Purnell, M.A. 1999. Growth, function, and the conodont fossil record. Geology, 27: 251-254.

Donoghue, P.C.J., Forey, P.L. \& Aldridge, R.J. 2000. Conodont affinity and chordate phylogeny. Biological Reviews, 75: 191-251.

Dzik, J. 2002. Emergence and collapse of the Frasnian conodont and ammonoid communities in the Holy Cross Mountains, Poland. Acta Palaeontologica, 47: 565-650.

Fåhraeus, L.E. 1982. Palmatolepis conodont apparatuses - Empirically derived composition and structure (Conodontophorida, Upper Devonian). Geologica et Palaeontologica, 16: 111-118.

Girard, C., Renaud, S. \& Sérayet, A. 2004. Morphological variation of Palmatolepis Devonian conodonts: species vs. genus. Comptes Rendus Palevol, 3: 1-8.

Girard, C., Klapper, G. \& Feist, R. 2005. Subdivision of the terminal Frasnian linguiformis conodont Zone, revision of the correlative interval of Montagne Noire Zone 13, and discussion of stratigraphically significant associated trilobites. Development in Palaeontology and Stratigraphy Series, 20: 181-198.

Gross, W. 1960. Über die Basis bei den Gattungen Palmatolepis und Polygnathus (Conodontida). Palaeontologische Zeitschrift, 34: 40-58.

Johnson, J.G., Klapper, G. \& Sandberg, C.A. 1985. Devonian eustatic fluctuations in Euramerica. Geological Society of America Bulletin, 96: $567-587$.

Kaufmann, B. 2006. Calibrating the Devonian Time Scale: a synthesis of $\mathrm{U}-\mathrm{Pb}$ ID-TIMS ages and conodont stratigraphy. Earth Science Reviews, 76: 175-190.

Klapper, G. \& Foster, C.T. Jr 1993. Shape analysis of Frasnian species of the Late Devonian conodont genus Palmatolepis. Paleontological Society Memoir, 32: 1-35.

Klapper, G. \& Johnson, J.G. 1980. Endemism and dispersal of Devonian conodonts. Journal of Paleontology, 54: 400-455.

Klapper, G. \& Philip, G.M. 1971. Devonian conodont apparatuses and their vicarious skeletal elements. Lethaia, 4: 429-452.

Klapper, G., Uyeno, T.T., Armstrong, D.K. \& Telford, P.G. 2004. Conodonts of the Williams Island and Long Rapids Formations (Upper Devonian, Frasnian-Famennian) of the Onakawana B drillhole, Moose River Basin, northern Ontario, with a revision of lower Famennian species. Journal of Paleontology, 78: 371-387.

Kucera, M. \& Darling, K.F. 2002. Cryptic species of planktonic foraminifera: their effect on palaeoceanographic reconstructions. Philosophical Transactions of the Royal Society, London Series A, 360: 695-718.

Lange, F.G. 1968. Conodonten-Gruppenfunde aus Kalken des tieferen Oberdevon. Geologica et Palaeontologica, 1: 97-114.

Mayr, E. 1957. Species concepts and definitions. In: Mayr, E. (Ed.), The Species Problem. American Association Advance Science Publications, Washington, 1-22.

Michaux, J. 1971. Données nouvelles sur les Muridae (Rodentia) Néogènes d'Europe sud-occidentale. Evolution et rapports avec les formes actuelles. Paléobiologie Continentale, 2: 1-67.

Misonne, X. 1969. African and Indo-Australian Muridae. Evolutionary trends. Annales du Musée Royal de l'Afrique Centrale, Tervuren, Belgique, 172: 1-219. 
Monteiro, L.R. 1999. Multivariate regression models and geometric morphometrics: the search for causal factors in the analysis of shape. Systematic Biology, 48: 192-199.

Morrow, J. 2000. Shelf-to-basin lithofacies and conodont paleoecology across Frasnian-Famennian (F-F, mid-Late Devonian) boundary, Central Great Basin (Western U.S.A.). Courier Forschungsinstitut Senckenberg, 219: 1-57.

Müller, K.J. 1956. Die Gattung Palmatolepis. Abhandlungen der senckenbergischen naturforschenden Gesellschaft, 494: 1-70.

Nicoll, R.S. 1987. Form and function of the Pa element in the conodont animal. In: Aldridge, R.J. (Ed.), Palaeobiology of conodonts. British Micropalaeontological Society, Chichester, 77-90.

Puchkov, V.N., Klapper, G. \& Mashkova, T.V. 1981. Natural assemblages of Palmatolepis from the upper Devonian of the northern Urals. Acta Palaeontologica Polonica, 26: 281-298.

Purnell, M.A. 1994. Skeletal ontogeny and feeding mechanisms in conodonts. Lethaia, 27: 129-138.

Purnell, M.A. \& von Bitter, P.H. 1992. Blade-shaped conodont elements functioned as teeth. Nature, 359: 629-631.

Raff, R.A. 1996. The shape of life. Genes, development, and the evolution of animal form. The University of Chicago Press, Chicago and London, 520pp.

Renaud, S. 1999. Size and shape variability in relation to species differences and climatic gradients in the African rodent Oenomys. Journal of Biogeography, 26: 857-865.

Renaud, S. \& Girard, C. 1999. Strategies of survival to extreme environmental perturbations: evolution of conodonts in response to the Kellwasser crisis (Upper Devonian). Palaeogeography, Palaeoclimatology, Palaeoecology, 146: 19-32.

Renaud, S. \& Schmidt, D.N. 2003. Habitat tracking as a response of the planktic foraminifer Globorotalia truncatulinoides to environmental fluctuations during the last 140 kyr. Marine Micropaleontology, 49: 97-122.

Renaud, S., Ziveri, P. \& Broerse, A.T.C. 2002. Geographical and seasonal differences in morphology and dynamics of the coccolithophore Calcidiscus leptoporus. Marine Micropaleontology, 46: 363-385.

Sandberg, C.A., Ziegler, W., Dreesen, R. \& Butler, J.L. 1988. Late Frasnian mass extinction: conodont event stratigraphy, global changes, and possible causes. Courier Forschungsinstitut Senckenberg, 102: $263-307$.
Sandberg, C.A., Morrow, J.R. \& Ziegler, W. 2002. Late Devonian sea-level changes, catastrophic events, and mass extinctions. Geological Society of America Special Paper, 356: 473-487.

Schindler, E. 1993. Event-stratigraphic markers within the Kellwasser Crisis near the Frasnian/Famennian boundary (Upper Devonian) in Germany. Palaeogeography, Palaeoclimatology, Palaeoecology, 104: $115-125$.

Schülke, I. 1995. Evolutive Prozesse bei Palmatolepis in der frühen Famenne-Stufe (Conodonta, Ober-Devon). Göttinger Arbeiten zur Geologie und Pälaontologie, 67: 1-108.

Scotese, C.R. \& Golonka, J. 1992. PALEOMAP Paleogeographical Atlas, PALEOMAP Progress Report n. 20. Department of Geology, University of Texas at Arlington.

Scotese, C.R. \& McKerrow, W.S. 1990. Revised world maps and introduction. In: McKerrow, W.S. \& Scotese, C.R. (Eds), Palaeozoic Palaeogeography and Biogeography. Geological Society, London, Memoirs, 12: 1-24.

Streelman, J.T., Webb, J.F., Albertson, R.C. \& Kocher, T.D. 2003. The cusp of evolution and development: a model of cichlid tooth shape diversity. Evolution \& Development, 5: 600-608.

Sweet, W.C. 1988. The Conodonta: Morphology, taxonomy, paleoecology, and evolutionary history of a long-extinct animal phylum. Oxford Monographs on Geology and Geophysics. Oxford, New York, 212pp.

Ta Hoa Phuong 1998. Upper Devonian Conodont Biostratigraphy in Viêt Nam. Journal of Geology, Series B, 11-12: 76-84.

von Bitter, P.H. \& Purnell, M.A. 2005. An experimental investigation of post-depositional taphonomic bias in conodonts. Special Papers in Palaeontology, 73: 39-56.

Ward-Campbell, B.M.S., Beamish, F.W.H. \& Kongchaiya, C. 2005. Morphological characteristics in relation to diet in five coexisting Thai fish species. Journal of Fish Biology, 67: 1266-1279.

Willerslev, E. \& Cooper, A. 2005. Ancient DNA. Review Paper. Proceedings of the Royal Society, London Series B, 272: 3-16.

Zhuravlev, A.V. 1995. Ontogeny and trophic types of some Tournaisian Polygnathacea (Conodonta). Courier Forschungsinstitut Senckenberg, 182: 307-312.

Ziegler, W. \& Sandberg, C.A. 1990. The late Devonian standard conodont zonation. Courier Forschungsinstitut Senckenberg, 121: $1-115$. 